Assiut Scientific Nursing Journal

http://asnj.journals.ekb.eg

http://www.arabimpactfactor.com

\title{
Effectiveness of Structured Self-Care Model on Self-Care, Disability and Pain among Patients with Rheumatoid Arthritis
}

\author{
Mona Mohamed Ibrahim ${ }^{1} \&$ Asmaa Ghareeb Momed ${ }^{2}$. \\ 1. Lecturer of Medical Surgical Nursing, Faculty of Nursing, Beni -Seuif University, Egypt. \\ 2. Assistant Professor of Community Health Nursing, Faculty of Nursing, Assiut University, Egypt.
}

\begin{abstract}
Background: Rheumatoid arthritis causes progressive deterioration, with subsequent functional decline leading to disability Aim: To investigate the effect of structured self-care model on of self-care, disability and pain among patients with rheumatoid arthritis. Design: quasi experimental study design was used. A convenience sample of 60 adult patients, drawn from all the patients in outpatient clinic at Mansoura University Hospital from January 2019 to October 2019. Tool: An interview questionnaire include: Socio-demographic and medical data, Exercise for Self Care Agency, World Health Organization Disability Assessment Schedule and Pain Disability Index (PDI). Results: Shows the patient get higher scores regarding level of exercise for Self Care Agency in follow up after 2 month (mean 119.9) and after 4month (mean 165.7) than pre-test (mean 104.9), as higher scores indicate higher level of self-care, with highly statistically significant difference (p.v 0.01). There was a highly statistically significant difference (p.v $0.001^{* *}$ ) regarding the mean score of the total disability assessment pre, after two and after four months among participant as the mean after four months (98.8 \pm 6.71$)$ was increased compared with the mean pretest (160.48 \pm 3.7$)$. Results shows the main items of pain disability index, pre, post two months and four months there a statistical significant regarding family and home responsibilities, recreation, social activity, life-support activity, occupation and total score. No statistical significant regarding sexual behavior .Conclusion $\boldsymbol{\&}$ Recommendations. A structured self-care model help in improvement of self-care, disability and pain level among patients with rheumatoid arthritis. Self-management programs result in beneficial effect on disability and pain scores.
\end{abstract}

\section{Keywords: Disability, Pain, Patients, Rheumatoid, Self-Care Model, Self-Care Agency \& Arthritis.}

\section{Introduction}

Rheumatoid Arthritis (RA) is an autoimmune disease which characterized by a chronic symmetrical polyarthritis of large and small joints, and by morning stiffness, which can lead to musculoskeletal impairment, and functional disabilities. The burden of disease course varies and the prediction of the prognosis is difficult to estimate. In the long term, RA reduced function which leads to difficulties of doing daily living activities (ADL), and subsequently impact negatively on psychosocial aspect (Aladdin et al., 2018).

RA affecting 0.5 to $1 \%$ of the adult population of developed regions with predominance of 2 to 3 times more in females. It affects all age groups but is more prevalent among 40 to 60 years people. It affects all age groups but is more prevalent among 40 to 60 years people. In rural Egypt, prevalence of up to $0.3 \%$ was found in the adult population (Smolen et al., 2016).

The most important and widespread symptom of this disease is pain. Pain is the main concern of patients with rheumatoid arthritis, and therefore is the main concern of health care providers. Pain is one of the determinants of disability in rheumatoid arthritis as along with self-esteem, fatigue, depression and motor limitation which are some of the outcomes of pain (Elahe et al., 2018). People with rheumatoid arthritis (RA) suffer increased risk of disability and premature mortality. Health enhancing physical activity (HEPA) could be one important factor to reduce this risk. Rising health care costs call for the development and evaluation of new modes of rehabilitation, including physical activity in settings outside the health care system (Nordgren et al., 2010).

Patients with rheumatoid arthritis can be responsible for managing their symptoms daily in the home and for a long time, and self-care education is one of the non-medical aspects of managing the disease. People with RA are recommended to use a wide variety of self-care methods to reduce pain and inflammation, the risk of deformities developing and to maintain or improve grip strength and hand function. The use of self-care methods relies on the patient's belief in the benefit of the methods and on their compliance with them (Ovayolu et al., 2012). 
The most commonly used index to measure the functional ability and its limitations among RA patients has been Health Assessment Questionnaire Disability Index (Bruce \&Fries 2005). In order to reduce RA symptoms and empower the patients, it is required to educate patients on arthritis management. Individuals with RA may play an essential role in the control of their disease. Extensive educational programs such as Arthritis Self- Management Program are recommended, which help to reduced disability (Hootman et al., 2012).

\section{Significance of the study}

RA may lead to a severe decline in functional status and a shortened life expectancy. In addition to the physical manifestations of the disease, there are often significant psychological and social consequences of living with RA. For example, pain and physical limitations were perceived as major stressors (Sato et al., 2008) Nurses help patients with RA achieve the ultimate goal of remission or low disease activity. Based on the patient's individual needs, encourage and assist him or her to establish health behaviors and activities that promote rest and exercise, reduce stress, and encourage independence.

Aim of the study

The aim of this study was to investigate the effect of structured self-care model on of self-care behavior, disability and pain for patients with rheumatoid arthritis.

\section{Subjects and Method}

Research hypotheses:

H1: Patients' ability to undertake self-care activities will be higher after implementing a structured selfcare model.

$\mathrm{H} 2$ : Patients level of disability and pain will reduce after implementation of structured self-care model.

\section{Research variables}

Independent variables

The Independent variables in the study is structured self-care model.

Dependent variables

Dependent variables are self-care agency, disability and pain level.

\section{Conceptual and theoretical framework}

Self-care is an important tool in controlling pain and disability in patients with rheumatoid arthritis. Orem model served as the theoretical framework for this study, when self-care is unable to provide own selfcare needs of patients, we need nursing systems to maintain health. In this model, three types of care system are designed based on needs and deviations from patient health: wholly compensatory system, partly compensatory system, and supportiveeducative system. Examples of wholly compensatory are provide the patient with full information about the disease, risk factors, clinical manifestation medical treatment, joint protection methods, and types of exercise, principles and correct food patterns. Examples supportive-educative are Pain control strategies, strategies for stress management and progressive anxiety doing of proper of exercises.

\section{Subjects and methods}

Study design

A quasi experimental study design with pre and post assessments was used in this study.

Study design and setting

This study was carried out at the rheumatology out patients' clinic at Mansoura University Hospital in Egypt.

\section{Subjects}

The study involved a convenience sample of 60 adult patients, drawn from all the patients in outpatient clinic for rheumatology from January 2019 to October 2019. The criteria for selection were: patients' age ranged between 18-65 years old; did not have any auditory, visual or psychological problems. The data were collected by the researchers using the face-to-face interview method.

Tools of data collection

Four tools were used for data collection, they accomplished after reviewing the recent relevant literatures

Tool (I): Socio-demographic and medical clinical base line data

This tool was developed by the researchers after reviewing of relevant literature. It was comprised of two parts including:-

Part I: Demographic characteristics questionnaire Demographic data and medical information sheet was designed by the researcher to elicit subjects': age, gender, marital status, level of education, occupation, family income, treatment payment system......etc.

Part II: Health history

It revealed all data about present\& past health history, family history, and duration of disease.

Tool (II): Exercise for Self Care Agency Scale

The Exercise of Self-care Agency tool was developed be Yamashita. (1998). It is self-administered with 43 items on a Likert-type scale of one to five with five indicating "very characteristic" and one indicating "very uncharacteristic.

Self-care agency was assessed using the Exercise of Self-care Agency (ESCA) Scale. This selfadministered instrument consists of four subscales, including active versus passive response to situations, motivations, the knowledge base, and the sense of self-worth. It has 43 items on a 5-point Likert-type scale ranging from 0 (it does not describe me) to 5 (it completely describes me). The total score ranges from 0 to 172 , which is equally divided into three levels: low (<56.76), moderate (56.76-113.52), and high 
(>113.52). Higher scores indicate higher level of selfcare agency.

Tool (III): World Health Organization Disability Assessment Schedule 2.0 (WHODAS 2.0)

World Health Organization. (2000) is a 36component measure that assesses disability in adults 18 years of age and older. Disability is evaluated in six areas, including: cognition, mobility, self-care, getting along, life activities, and participation- joining in community activities.

WHODAS 2.0 Summary Scores: There are two basic options for calculating summary scores for WHODAS 2.0's 36 full version item.

Scores assigned to each of the items "none" (1), "moderate" (2), "moderate" (3), "severe" (4), and "extreme" (5) - are summed up. This method is referred to as simple scoring because the scores of each of the items are simply added without re-coding or breakdown of the response classes; Hence, there is no weighting of individual varieties. This approach is practical to use a hand-scoring approach, and the method of choice can be in busy health facilities or in paper-and-pencil interview situations. As a result, a small amount of scores of items across the board constitutes an insufficient statistic to describe the degree of job restrictions.

He scored three steps:

- Step 1 - Summarize the coded item scores in each domain.

- Step 2 - Summarize all six scale scores.

- Step 3 - Conve

rt the summary score into a scale ranging from 0 to 100

(Where $0=$ no disability; $100=$ complete disability

Tool (IV): The Pain Disability Index (PDI):

It was adapted by (Tait et al., 1990). It was used for measuring the impact that pain has on the ability of a person to participate in essential life activities. Item of this scale were measure: Family and home responsibilities; recreation:, social activity ;occuation, sexual behavior and self care, life-support activity

Scoring system: the patient uses an 11-point range ranging from 0 (i.e. disability) to 10 (total deficit). The overall score is obtained by summing the responses to the seven items

Validity and reliability of the tools

Validity of tools was done by 7 experts from medical and nursing field to check the relevancy, clarity, comprehensiveness, and applicability of the questions. According to their opinions, minor modifications were done and the final form was developed. The reliability of the tool was tested using the internal consistency method. It was found that Cronbach's alpha reliability coefficient was 0.85

\section{Ethical consideration}

An approval to conduct the study was obtained from the director of Rheumatology out Patients Clinics at Mansoura University Hospital in Egypt after applying complete explanation provided by the researcher regarding the aim of the study. Verbal consent was obtained from each patient to be included in the study after explaining the aim and importance as well as stressing on confidentiality of the collected data. The researcher emphasized that the participation on the study are absolutely voluntary and each patient has the right to withdraw from the study without explaining any reason. The process of data collection did not disturb the harmony of the work. All data collected were used for the study purpose only and were processed in total confidentiality.

Pilot study

Pilot study was conducted on $10 \%$ of patients. This number was excluded from the studied sample to identify the obstacles and problems that may be encountered in data collection, applicability and feasibility of the tools.

Field work

The study was done from the beginning of January 2019 to end of October 2019. Data were collected by the researcher three days per week, during the morning shift from 9Am to $2 \mathrm{Pm}$.

Data were collected in the following sequence

Assessment phase: the study protocol was approved and an official permission from director of rheumatology out patients clinic at Mansoura University Hospital, Egypt to carry out the study after identification of the purpose of the study. The data were collected throughout two phase of assessment by using four tools. The first phase of assessment was collected prior to conducting the structured self care model to have base line about patient condition and observe and measure patient outcome through self care on behavior, disability level and pain level.

\section{Planning Phase}

Development of the structured self care model was based on analysis of the collected data. It was developed guided by reviewing the most recent related literature; the researchers developed a training program for patients using teaching aids and media, video and also Arabic handouts.

\section{Implementation phase}

Data were collected at Rheumatology out Patients Clinic at Mansoura University Hospital, Egypt. This program covered by 4 sessions with $10-15$ patient in each cession including theoretical and practical training regarding self-care. In addition, the researcher joins family members in educational sessions for providing a suitable home environment to subjects by their participation. Each session take 3045 hours. The researchers provide a full explanation 
of the disease, then display pictures and a video about proper exercise then patients are provided with simplified booklets. Finally, providing educational pamphlets at the end of each session as guidance for patients. Additionally, the researcher's contact numbers were given to patients to take action if they had a problem or question. Self-care behaviors based on the structured self care model were used by the intervention group for four months. This phase covered a period of 4 months beginning of January 2019 to end of April 2019.

\section{Self-care model}

Covered the following main items regarding rheumatoid arthritis and how to deal with it including:

- Knowledge about rheumatoid arthritis as definition causes, risk factors, clinical manifestation medical treatment.

- Joint protection methods.

- Types of exercise.

- Principles and correct food patterns.
- Medical regimen for treatment and prevention recurrence of disease.

- Pain control strategies.

- Strategies for stress management and progressive anxiety.

\section{Evaluation phase}

in the last phase of program, each patient was evaluated via scheduling meeting with them at the same day for his/her follow up appointment or by telephone calls. In evaluation phase the subject was evaluated two times. First time carried out after two months from completion of the implementation of structured self care model. The second time two months from the first post assessment. The subject was evaluated by using the same tools that mentioned before to assess the effectiveness of the structured self care model on self care behavior, disability level and pain level of all subjects. This phase covered a period of 4 months beginning of May 2019 to end of October 2019.

\section{Statistical analysis}

\section{Results}

Tool I: Socio-demographic \& medical data

Table (1): Demographic characteristics among participants $n=60$.

\begin{tabular}{|c|c|c|}
\hline Items & $\mathbf{N}$ & $\%$ \\
\hline Age (Mean \pm SD) & \multicolumn{2}{|c|}{$39.50 \pm 6.997$} \\
\hline Gender (Female ) & 60 & 100.0 \\
\hline \multicolumn{3}{|l|}{ Marital status } \\
\hline single & 2 & 3.3 \\
\hline married & 55 & 91.7 \\
\hline widow & 3 & 5.0 \\
\hline \multicolumn{3}{|l|}{ level of education } \\
\hline illiterate & 41 & 68.3 \\
\hline read and write & 15 & 25.0 \\
\hline middle education & 3 & 5.0 \\
\hline high education & 1 & 1.7 \\
\hline \multicolumn{3}{|l|}{ Job } \\
\hline working & 17 & 28.3 \\
\hline not working & 43 & 71.7 \\
\hline \multicolumn{3}{|l|}{ Residence } \\
\hline urban & 18 & 30.0 \\
\hline rural & 42 & 70.0 \\
\hline \multicolumn{3}{|l|}{ Family income } \\
\hline insufficient & 60 & 100.0 \\
\hline \multicolumn{3}{|c|}{ Treatment payment system } \\
\hline health insurance & 14 & 23.3 \\
\hline government expense & 46 & 76.7 \\
\hline \multicolumn{3}{|l|}{ Duration of disease } \\
\hline 6 month -1 year & 13 & 21.7 \\
\hline 1 year $>3$ year & 30 & 50.0 \\
\hline years - 5 years & 17 & 28.3 \\
\hline
\end{tabular}


Table (2): Medical clinical base line data.

\begin{tabular}{|l|c|c|c|c|}
\hline \multirow{2}{*}{\multicolumn{1}{c|}{ Items }} & \multicolumn{2}{c|}{ No } & \multicolumn{2}{c|}{ yes } \\
\cline { 2 - 5 } & $\mathbf{N}$ & \% & N & 25.0 \\
\hline Arthralgia & 45 & 75.0 & 15 & 66.7 \\
\hline Fatigue & 20 & 33.3 & 40 & 86.7 \\
\hline Pain & 8 & 13.3 & 52 & 46.7 \\
\hline Stiffness & 32 & 53.3 & 28 & 100.0 \\
\hline Disability & 0 & 0 & 60 & 70.0 \\
\hline Swelling & 18 & 30.0 & 42 & 46.7 \\
\hline Chronic Disease & 32 & 53.3 & 28 & 25.0 \\
\hline HTN & 45 & 75.0 & 15 & 6.7 \\
\hline Cardiac & 56 & 93.3 & 4 & 21.7 \\
\hline DM & 47 & 78.3 & 13 & 3.3 \\
\hline Osteoporosis & 58 & 96.7 & 2 & 26.7 \\
\hline FH & 44 & 73.3 & 16 & 25.0 \\
\hline Degree & & & & 1.7 \\
\hline First degree & 0 & 0.0 & 15 & \\
\hline Second degree & 0 & 0.0 & 1 & \\
\hline
\end{tabular}

Tool (II): Exercise for Self Care Agency

Table (3): mean level of Exercise for Self Care Agency pre and post structured self-care model $n=60$

\begin{tabular}{|l|r|r|r|r|r|r|}
\hline \multicolumn{1}{|c|}{ Items } & \multicolumn{1}{c|}{ N } & Mean & Std. Deviation & \multicolumn{1}{c|}{ Minimum } & Maximum & p.v \\
\hline Pre- test & 60 & 104.9000 & 3.27652 & 97.00 & 111.00 & \\
\hline after 2 month & 60 & 119.9000 & 8.01630 & 97.00 & 140.00 \\
\hline after 4month & 60 & 165.6667 & 2.72258 & 161.00 & 173.00 & .001 \\
\hline Total & 180 & 130.1556 & 26.43699 & 97.00 & 173.00 & \\
\hline
\end{tabular}

Higher scores indicate higher level of self-care agency.

Table (4): Frequency distribution among participant regarding exercise for Self Care.

\begin{tabular}{|c|c|c|c|c|c|c|}
\hline \multirow{2}{*}{\multicolumn{3}{|c|}{ Total score $35-175$}} & \multicolumn{3}{|c|}{ follow-up } & \multirow{2}{*}{ Total } \\
\hline & & & Pretest & After 2 month & After 4month & \\
\hline \multirow{6}{*}{$\begin{array}{l}\text { Self-care } \\
\text { agency }\end{array}$} & \multirow{2}{*}{ low $(<56.76)$} & $\mathrm{N}$ & 0 & 0 & 0 & \multirow{6}{*}{.001} \\
\hline & & $\%$ & 0 & 0 & 0 & \\
\hline & \multirow{2}{*}{\begin{tabular}{|l|} 
moderate self care \\
$(56.76-113.52)$
\end{tabular}} & $\mathrm{N}$ & 60 & 10 & 0 & \\
\hline & & $\%$ & 100.0 & 16.7 & $0.0 \%$ & \\
\hline & \multirow{2}{*}{$\begin{array}{l}\text { High self care } \\
(>113.52) .\end{array}$} & $\mathrm{N}$ & 0 & 50 & 60 & \\
\hline & & $\%$ & $0.0 \%$ & $83.3 \%$ & $100.0 \%$ & \\
\hline
\end{tabular}

Agency follow up $\quad n=60$

Tool (III): World Health Organization Disability Assessment

Table (5): World Health Organization Disability Assessment pre and post structured self-care model

\begin{tabular}{|l|c|c|c|c|c|c|}
\hline \multicolumn{7}{|c|}{ Understanding and communicating score 6-30 } \\
\hline & $\mathbf{N}$ & Mean & Std. Deviation & Minimum & Maximum & p.v \\
\hline \hline pretest & 60 & 19.1000 & 1.18893 & 17.00 & 22.00 & \\
\hline after 2 month & 60 & 18.6000 & 1.31742 & 16.00 & 22.00 & .001 \\
\hline after 4month & 60 & 7.4833 & 1.01667 & 6.00 & 11.00 & \\
\hline Total & 180 & 15.0611 & 5.50385 & 6.00 & 22.00 & \\
\hline \multicolumn{7}{|c|}{ Getting around score 5-25 } \\
\hline pretet & 60 & 23.5167 & .99986 & 21.00 & 25.00 & \multirow{2}{*}{.001} \\
\hline after 2 month & 60 & 19.1667 & 1.09183 & 17.00 & 21.00 & \\
\hline
\end{tabular}




\begin{tabular}{|c|c|c|c|c|c|c|}
\hline \multicolumn{6}{|c|}{ Understanding and communicating score 6-30 } & \multirow{4}{*}{ p.v } \\
\hline & $\mathbf{N}$ & Mean & Std. Deviation & Minimum & Maximum & \\
\hline after 4month & 60 & 12.1167 & 2.06744 & $\overline{8.00}$ & 16.00 & \\
\hline Total & 180 & 18.2667 & 4.93149 & 8.00 & 25.00 & \\
\hline \multicolumn{7}{|c|}{ Total self-care 4-20 } \\
\hline pretet & 60 & 17.3667 & 1.13446 & 15.00 & 19.00 & \multirow{4}{*}{.001} \\
\hline after 2 month & 60 & 17.3667 & 1.13446 & 15.00 & 19.00 & \\
\hline after 4month & 60 & 8.1167 & 1.59546 & 5.00 & 11.00 & \\
\hline Total & 180 & 14.2833 & 4.56153 & 5.00 & 19.00 & \\
\hline \multicolumn{7}{|c|}{ Getting along with people Score 5-25 } \\
\hline pretest & 60 & 21.0833 & 1.44142 & 17.00 & 24.00 & \multirow{4}{*}{.001} \\
\hline after 2 month & 60 & 9.6167 & 1.35411 & 5.00 & 12.00 & \\
\hline after 4month & 60 & 9.2500 & 1.11424 & 6.00 & 12.00 & \\
\hline Total & 180 & 13.3167 & 5.66127 & 5.00 & 24.00 & \\
\hline \multicolumn{7}{|c|}{ Total activity $8-40$} \\
\hline pretet & 60 & 42.1833 & 2.36852 & 37.00 & 44.00 & \multirow{4}{*}{.001} \\
\hline after 2 month & 60 & 42.1833 & 2.36852 & 37.00 & 44.00 & \\
\hline after 4month & 60 & 35.4000 & 4.30687 & 24.00 & 40.00 & \\
\hline Total & 180 & 39.9222 & 4.48269 & 24.00 & 44.00 & \\
\hline \multicolumn{7}{|c|}{ Participation in society Score 8-40 } \\
\hline pretest & 60 & 37.2333 & .85105 & 36.00 & 39.00 & \multirow{4}{*}{.001} \\
\hline after 2 month & 60 & 33.8500 & 1.31259 & 31.00 & 37.00 & \\
\hline after 4month & 60 & 26.3833 & 1.57407 & 23.00 & 29.00 & \\
\hline Total & 180 & 32.4889 & 4.72068 & 23.00 & 39.00 & \\
\hline \multicolumn{7}{|c|}{ Total disability assessment $36-180$} \\
\hline pretest & 60 & 160.4833 & 3.66611 & 153.00 & 167.00 & \multirow{4}{*}{.001} \\
\hline after 2 month & 60 & 140.7833 & 3.14126 & 134.00 & 148.00 & \\
\hline after 4month & 60 & 98.7500 & 6.70852 & 84.00 & 110.00 & \\
\hline Total & 180 & 133.3389 & 26.25065 & 84.00 & 167.00 & \\
\hline
\end{tabular}

Table (6): Level disability Assessment pre and post structured self-care model.

\begin{tabular}{|c|c|c|c|c|c|}
\hline \multirow[b]{2}{*}{ Level of disability } & & \multicolumn{3}{|c|}{ Follow up } & \multirow[b]{2}{*}{ Total } \\
\hline & & pretest & $\begin{array}{l}\text { after } 2 \\
\text { month }\end{array}$ & $\begin{array}{c}\text { after } \\
\text { 4month }\end{array}$ & \\
\hline \multirow[t]{2}{*}{ Mild disability total score 72 less 108} & $\mathrm{~N}$ & 0 & 0 & 51 & \multirow{6}{*}{.001} \\
\hline & $\%$ & 0.0 & 0.0 & 85.0 & \\
\hline \multirow[t]{2}{*}{ Moderate disability score 108 less 144} & $\mathrm{~N}$ & 0 & 54 & 9 & \\
\hline & $\%$ & 0.0 & 85.7 & 14.3 & \\
\hline \multirow[t]{2}{*}{ Sever disability score 144 -less 180} & $\mathrm{~N}$ & 60 & 6 & 0 & \\
\hline & $\%$ & 100.0 & 9.1 & 0.0 & \\
\hline
\end{tabular}

Table (7): Pain Disability pre and post structured self-care model.

\begin{tabular}{|l|c|c|c|c|c|}
\hline The Pain Disability total 7-35 score & Mean & Std. Deviation & Minimum & Maximum & \\
\hline Pretest & 27.3333 & .93277 & 25.00 & 29.00 & \\
\hline after 2 month & 27.3333 & .93277 & 25.00 & 29.00 & .001 \\
\hline after 4month & 19.6167 & 1.09066 & 17.00 & 22.00 & \\
\hline Total & 24.7611 & 3.77786 & 17.00 & 29.00 & \\
\hline
\end{tabular}


Table (8): The Pain Disability Index (PDI).

\begin{tabular}{|c|c|c|c|c|c|c|c|c|c|c|c|c|}
\hline \multirow[t]{2}{*}{ The Pain Disability } & \multirow{2}{*}{$\begin{array}{l}\text { Follo } \\
\text { w up }\end{array}$} & \multicolumn{2}{|c|}{$\begin{array}{c}\text { No } \\
\text { disability }\end{array}$} & \multicolumn{2}{|c|}{$\begin{array}{c}\text { Mild } \\
\text { disability }\end{array}$} & \multicolumn{2}{|c|}{$\begin{array}{l}\text { Moderate } \\
\text { disability }\end{array}$} & \multicolumn{2}{|c|}{$\begin{array}{c}\text { Sever } \\
\text { disability }\end{array}$} & \multicolumn{2}{|c|}{$\begin{array}{c}\text { Worst } \\
\text { disability }\end{array}$} & \multirow[t]{2}{*}{$\mathbf{P}$} \\
\hline & & $\mathbf{n}$ & $\%$ & $\mathbf{n}$ & $\%$ & $\mathbf{n}$ & $\%$ & $\mathbf{n}$ & $\%$ & $\mathbf{n}$ & $\%$ & \\
\hline \multirow{3}{*}{$\begin{array}{l}\text { family and home } \\
\text { responsibilities: } \\
\text { activities related to } \\
\text { home and family }\end{array}$} & Pre-test & 0 & 0 & 0 & 0 & 0 & 0 & 12 & 20.0 & 48 & 80.0 & \multirow{3}{*}{.001} \\
\hline & Post $2 \mathrm{~m}$ & 0 & 0 & 0 & 0 & 0 & 0 & 12 & 20.0 & 48 & 80.0 & \\
\hline & Post $4 m$ & 0 & 0 & 0 & 0 & 27 & 45.0 & 28 & 46.7 & 5 & 8.3 & \\
\hline \multirow{3}{*}{$\begin{array}{l}\text { Recreation: hobbies } \\
\text { sports and other } \\
\text { leisure time activities }\end{array}$} & Pre-test & 0 & 0 & 0 & 0 & 0 & 0 & 0 & 0 & 60 & 100.0 & \multirow{3}{*}{.001} \\
\hline & Post $2 \mathrm{~m}$ & 0 & 0 & 0 & 0 & 0 & 0 & 0 & 0 & 60 & 100.0 & \\
\hline & Post $4 m$ & 0 & 0 & 0 & 0 & 60 & 100.0 & 0 & 0 & 0 & 0 & \\
\hline \multirow{3}{*}{$\begin{array}{l}\text { Social activity: } \\
\text { participation with } \\
\text { friends and } \\
\text { acquaintances other } \\
\text { than family members }\end{array}$} & Pre-test & 0 & 0 & 0 & 0 & 0 & 0 & 32 & 53.3 & 28 & 46.7 & \multirow{3}{*}{.001} \\
\hline & Post $2 \mathrm{~m}$ & 0 & 0 & 0 & 0 & 0 & 0 & 32 & 53.3 & 28 & 46.7 & \\
\hline & Post4m & 0 & 0 & 3 & 5.0 & 57 & 95.0 & 0 & 0 & 0 & 0 & \\
\hline \multirow{3}{*}{$\begin{array}{l}\text { Occupation: activities } \\
\text { partly or directly } \\
\text { related to working } \\
\text { including housework } \\
\text { or volunteering }\end{array}$} & Pre-test & 0 & 0 & 0 & 0 & 0 & 0 & 12 & 20.0 & 48 & 80.0 & \multirow{3}{*}{.001} \\
\hline & Post $2 \mathrm{~m}$ & 0 & 0 & 0 & 0 & 0 & 0 & 12 & 20.0 & 48 & 80.0 & \\
\hline & Post4m & 0 & 0 & 0 & 0 & 0 & 0 & 55 & 91.7 & 5 & 8.3 & \\
\hline \multirow{3}{*}{$\begin{array}{l}\text { Sexual behavior: } \\
\text { frequency and quality } \\
\text { of sex life }\end{array}$} & Pre-test & 0 & 0 & 0 & 0 & 0 & 0 & 14 & 23.3 & 46 & 76.7 & \multirow{3}{*}{.969} \\
\hline & Post $2 \mathrm{~m}$ & 0 & 0 & 0 & 0 & 0 & 0 & 14 & 23.3 & 46 & 76.7 & \\
\hline & Post4m & 0 & 0 & 0 & 0 & 0 & 0 & 17 & 28.3 & 43 & 71.7 & \\
\hline \multirow{3}{*}{$\begin{array}{l}\text { Self care: personal } \\
\text { maintenance and } \\
\text { independent daily } \\
\text { living }\end{array}$} & Pre-test & 0 & 0 & 0 & 0 & 0 & 0 & 0 & 0 & 60 & 100.0 & \multirow{3}{*}{.969} \\
\hline & Post $2 \mathrm{~m}$ & 0 & 0 & 0 & 0 & 0 & 0 & 0 & 0 & 60 & 100.0 & \\
\hline & Post4m & 0 & 0 & 0 & 0 & 0 & 0 & 60 & $\begin{array}{c}100 . \\
0\end{array}$ & 0 & 0 & \\
\hline \multirow{3}{*}{$\begin{array}{l}\text { life-support activity: } \\
\text { basic life-supporting } \\
\text { behaviors }\end{array}$} & Pre-test & 0 & 0 & 0 & 0 & 0 & 0 & 18 & 30.0 & 42 & 70.0 & \multirow{3}{*}{.001} \\
\hline & Post $2 \mathrm{~m}$ & 0 & 0 & 0 & 0 & 0 & 0 & 18 & 30.0 & 42 & 70.0 & \\
\hline & Post $4 \mathrm{~m}$ & 0 & 0 & 0 & 0 & 0 & 0 & 54 & 90.0 & 6 & 10.0 & \\
\hline \multirow[t]{3}{*}{ Total } & Pre-test & $\mathbf{0}$ & $\mathbf{0}$ & $\mathbf{0}$ & $\mathbf{0}$ & $\mathbf{0}$ & $\mathbf{0}$ & 13 & 21.7 & 47 & 78.3 & \multirow{3}{*}{.001} \\
\hline & Post2m & $\mathbf{0}$ & $\mathbf{0}$ & $\mathbf{0}$ & $\mathbf{0}$ & $\mathbf{0}$ & $\mathbf{0}$ & 13 & 21.7 & 47 & 78.3 & \\
\hline & Post4m & $\mathbf{0}$ & $\mathbf{0}$ & $\mathbf{0}$ & $\mathbf{0}$ & 21 & 35.0 & 31 & 51.7 & 8 & 13.3 & \\
\hline
\end{tabular}

Table (1): Shows that all of study sample was females, most of them were married their mean age

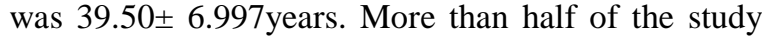
sample $(68.3 \%)$ was illiterate and live in urban areas. Regarding duration of disease, half of the patients were 1 year $>3$ year.

Table (2): Clarify that the majority of patients $(86.7 \%)$ have pain, also, more than two-third of patients $(70 . \%)$ have swelling. Around half of them $(46.7 \%)$ have chronic disease.

Table (3): Shows that the patient get higher scores regarding level of exercise for Self Care Agency in follow up after 2 month (mean 119.9) and after 4month (mean 165.7) than pre-test (mean 104.9), as higher scores indicate higher level of self-care ,with highly statistically significant difference (p.v 0.01).

Table (4): Shows that all patients (100.0\%) get moderate self-care (56.76-113.52) pretest, but most of them have high self-care (>113.52) after 2 month post application of self-care model on other hand $100.0 \%$ experience high self-care after 4 month posttest with highly statistically significant difference (p.v 0.01).

Table (5): Demonstrates that there are statistically significant differences regarding all items of world health organization disability assessment pre, after two and after four months among participant.

Table (6): Shows that there is a statistically significant difference regarding total disability assessment pre, after two and after four months among participant.

Table (7): Demonstrated that there was a highly statistically significant difference (p.v 0.01) regarding the mean score of the total pain assessment pre, after two and after four months

Table (8): This table shows the main items of pain disability index, pre, post two months and four months there a statistical significant regarding family 
and home responsibilities, recreation, social activity, life-support activity, occupation and total score. No statistical significant regarding sexual behavior and self-care

\section{Discussion}

Rheumatoid arthritis (RA) is a chronic systemic autoimmune disease that basically influences the covering of the synovial joints and is related with dynamic inability, sudden passing, and financial weights. RA is an intricate illness that influences every patient in an unexpected way. Individuals from every single ethnic foundation are in danger of creating RA. It considered as the third most basic kind of joint inflammation behind osteoarthritis and gout (Oliveira, 2020).

The aim of our study was to investigate the effect of structured self-care model on of self-care behavior, disability level and pain level for Patients with rheumatoid arthritis. So the discussion of the present study results will cover the following items: demographic, medical data, exercise for self-care agency, World Health Organization Disability Assessment and pain disability.

Regarding the exercise for self care agency, the current examination indicated that the patient get higher scores in regards to level of exercise for Self Care Agency in follow up after 2 month and after 4month than pre-test, with highly statistically significant difference. Likewise the investigation uncovered that all patients get moderate self-care pretest, yet the vast majority of them have high selfcare after 2 month post application of self-care model and experience high self-care after 4month post-test with highly statistically significant difference.

This indicated that the Structured Self-Care Model effected positively on the level of self care. The researcher The analyst conclusion, the absence of understanding about the intangible symptoms of RA such as pain and fatigue, and the potential long term joint damage and disability, would explain why many of the informants were 'struggling with normality' and unfit to reset or come back to normality. In view of the current study we contend that structured Self-care model capable of producing significant beneficial effects on self-efficacy function and pain among RA patients.

In a similar line, Genovese et al., (2019) found a $20 \%$ of the rheumatoid joint pain patients had high scores with respect to level of activity for self-care agency.

The discoveries in Nadrian et al., (2019) study test of RA patients show a moderate or more significant level of self-care agency present, including that; solitary a small amount of the gathering had low degrees of self-care agency. This reality underlines the requirement for people with RA to receive careful assessment and intervention to support and increase their self-care agency.

Our findings matches with Madsen et al., (2019) who found that here were statistically significant improvements in self-efficacy for functional ability and self-efficacy pain scale after administration of training program.

Also, Jönsson et al., (2018) found subsequent to finishing a preparation program in the intervention group showed statistically significant improvements in their levels of self-efficacy function and pain scores to manage their arthritis compared to that before the intervention.

Furthermore, Tirlea et al., (2016) presumed that; usage of activity practices may add to program completion and increasing aspects of self efficacy

Regarding World Health Organization disability assessment; the existing study demonstrated that there are statistically significant differences regarding all items of world health organization disability assessment pre, after two and after four months among the studied patients. In addition, there is a statistically significant difference regarding total disability assessment pre, after two and after four months among participant. Regarding the total disability assessment demonstrated it was increased compared with the mean pretest.

This demonstrated so as to diminish RA side effects (disability) and empower the patients, it is required to educate patients on arthritis management. This match with Sierakowska et al., (2017) study who found that health care program impact emphatically on rheumatic arthritis disability level.

In the same line, the study of Conigliaro et al., (2019) inferred that empowering women with RA by educational programs is fundamental because of the expanding number of bone and joint infections just as the extreme effects of RA on patient's personal satisfaction.

This study showed the main items of pain disability index, pre, post two months and four months, with a statistical significant regarding family and home responsibilities, recreation, social activity, lifesupport activity, occupation and total score but no statistical significant regarding sexual behavior and self-care. Our study found that patients' disability levels deteriorated and pain levels increased as their self-care agency score grew worse.

Consequently, for patients who can't realize self-care activities, the responsibility of the nurse is to help the person until he/she can complete his/her self-care activities, empower the person to attempt his/her own self-care and increment his/her life satisfaction to the maximum level (Chen et al., 2018). 
Similarly, there are other examination led Glapa et al., (2018) demonstrated that educational programs have emphatically influenced the improvement of states of being of the participants.

Generally, we likewise found that measures of functional status, self-care agency and pain scores are important in the evaluation of RA patients, not only for nursing research purposes but also in routine nursing care. As patients learn about self care behavior and acquire the capacity for self-care, their compliance and quality of life increases, complications are prevented and the expected lifetime is extended with the control of the disease. The present study finding revealed that there was a negative correlation was detected between self-care agency and disability level.

Gong \& Mao, (2016) results indicated that the importance attached by the individual to his/her health and care is related to the individual's will and capacity and his/her ability to practice daily activities without somebody else's help. This this is not supported by the Riegel et al., (2017) finding who concluded that no significant relationship was detected between disease period, self-care agency and disability level.

Finally, patients with RA may play an essential role in the control of their disease. extensive educational programs such as structured self-care model is recommended, which help to reduced disability It is clearly seen that, in particular, the low level of education and lack of information about the disease decreases the patients' possibility to develop positive behavior.

\section{Conclusion}

Findings of the current study concluded that implementing structured self-care model help in reducing disability and pain level among patients with rheumatoid arthritis.

\section{Recommendations}

Self-management program are recommended at it result in beneficial effect on disability and pain scores. Replicat this study in large probability sampling.

\section{References}

1. Aladdin A., Balbaa, Allam M., Koura, M., Alrawaili, R., Hamada, H., Khater H., (2018): The effect of Siwan therapy in management of patients with rheumatoid arthritis: a single blind randomized controlled trial, Biomedical Research 2018; 29 (7): 1400-1406.

2. Arvidsson S., Petersson A., Nilsson I., Andersson B., Arvidsson B., Petersson I., \&
Fridlund B., (2006): A nurse led rheumatology clinic's impact on empowering patients with rheumatoid arthritis: a qualitative study. Nursing \& Health Science 8, 133-139.

3. Bruce B., \& Fries J., (2005): The Health Assessment Questionnaire (HAQ). Clin Exp Rheumatol 23:14-18.

4. Chen, J., Zhao, H., Hao, S., Xie, J., Ouyang, Y., \& Zhao, S., (2018): Motivational interviewing to improve the self-care behaviors for patients with chronic heart failure: A randomized controlled trial. International journal of nursing sciences, 5(3), 213-217.

5. Conigliaro, P., Triggianese, P., De Martino, E., Fonti, G., Chimenti, M., Sunzini, F., \& Perricone, R., (2019): Challenges in the treatment of rheumatoid arthritis. Autoimmunity reviews, 18(7), 706713.

6. Elahe, S., Robabe, M., Fatahi S., Fatemeh G., (2018): Use of the Orem self-care model on pain relief in women with rheumatoid arthritis: a randomized trial,Electronic Physician (ISSN: 2008-5842),Volume: 10, Issue: 6, Pages: 6884-6891, DOI: http://dx.doi.org/10.19082/6884.

7. Genovese, M., Kalunian, K., Gottenberg, J., Mozaffarian, N., Bartok, B., Matzkies, F., \& De Vlam, K., (2019): Effect of filgotinib vs placebo on clinical response in patients with moderate to severe rheumatoid arthritis refractory to disease-modifying antirheumatic drug therapy: the FINCH 2 randomized clinical trial. Jama, 322(4), 315-325.

8. Glapa, A., Grzesiak, J., LaudanskaKrzeminska, I., Chin, M., Edginton, C., Mok, M., \& Bronikowski, M., (2018): The impact of brain breaks classroom-based physical activities on attitudes toward physical activity in polish school children in third to fifth grade. International journal of environmental research and public health, 15(2), 368 .

9. Gong, G., \& Mao, J., (2016): Health-related quality of life among Chinese patients with rheumatoid arthritis: the predictive roles of fatigue, functional disability, self-efficacy, and social support. Nursing research, 65(1), 55-67.

10. Grabovac, I., Haider, S., Berner, C., Lamprecht, T., Fenzl, K., Erlacher, L., \& Dorner, T., (2018): Sleep quality in patients with rheumatoid arthritis and associations with pain, disability, disease duration, and activity. Journal of clinical medicine, 7(10), 336. 
11. Hootman, J., Helmick, C., \& Brady, T., (2012): A public health approach to addressing arthritis in older adults: The most common cause of disability. American journal of public health, 102(3), S426-S433. doi:10.2105/AJPH.2011.300423.

12. Jönsson, T., Hansson, E., Thorstensson, C., Eek, F., Bergman, P., \& Dahlberg, L., (2018): The effect of education and supervised exercise on physical activity, pain, quality of life and self-efficacy-an intervention study with a reference group. BMC musculoskeletal disorders, 19(1), 198.

13. Madsen, U., Baath, C., Berthelsen, C., \& Hommel, A., (2019): Age and health-related quality of life, general self-efficacy, and functional level 12 months following dysvascular major lower limb amputation: a prospective longitudinal study. Disability and rehabilitation, 41(24), 2900-2909.

14. Nadrian, H., Niaz, Y., Basiri, Z., \& Roudsari, A., (2019): Development and psychometric properties of a self-care behaviors scale (SCBS) among patients with rheumatoid arthritis. BMC rheumatology, 3(1), 4.

15. Norgren, B., Fridén, C., Demmelmaier, I., Bergström, G., \& Opava, C., (2012): Longterm health-enhancing physical activity in rheumatoid arthritis-the PARA 2010 study. BMC Public Health, 12(1), 397.

16. Oliveira, S., (2020): Talking About Rare Diseases: A Compendium on Rare Diseases and Online News. In Communicating Rare Diseases and Disorders in the Digital Age (pp. 1-86). IGI Global

17. Ovayolu, O., Ovayolu, N., \& Karadag, G., (2012): The relationship between self-care agency, disability levels and factors regarding these situations among patients with rheumatoid arthritis. Journal of clinical nursing, 21(1-2), 101-110. https://doi.org/10.1111/j.13652702.2011.03710.x

18. Riegel, B., Moser, D., Buck, H., Dickson, V., Dunbar, S., Lee, C., \& Webber, D., (2017). Self-care for the prevention and management of cardiovascular disease and stroke: A scientific statement for healthcare professionals from the American Heart Association. Journal of the American Heart Association, 6(9), e006997.

19. Sato M., Yamazaki Y., Sakita M., \& Bryce T., (2008): Benefit-finding among people with rheumatoid arthritis in Japan. Nursing \& Health Sciences 10, 51-58
20. Sierakowska, M., Wysocka-Skurska, I., \& Kułak, W., (2017). Identification of demographic factors and health problems that affect the acceptance of disease and health behaviors of patients with osteoarthritis. PeerJ, 5, e3276.

21.Smolen, J., Aletena D., \& McInnes, I., (2016): Rheumatoid arthritis .The Lancet,388(10055).2023-2038.

22.Tait R., Chibnall J., Krause S., (1990): The Pain Disability Index: psychometric properties Pain;40:171-82.

23. Tirlea, L., Truby, H., \& Haines, T., (2016): Pragmatic, randomized controlled trials of the Girls on the Go! Program to improve selfesteem in girls. American journal of health promotion, 30(4), 231-241.

24. World Health Organization. (2000): World Health Organization disabilty assessment schedule: WHODAS II. Phase 2 field trials. Health services research.

25. Yamashita, M., (1998): The exercise of selfcare agency scale. Western Journal of Nursing Research, 20(3), 370-381.

26. Yuan, Z., Wang, J., Su, L., Xu, W.., \& Huang, A., (2019): Gene polymorphisms and serum levels of TL1A in patients with rheumatoid arthritis. Journal of cellular physiology, 234(7), 11760-11767. 